\title{
O (im)pacto federativo e financiamento da educação: algumas aproximações sobre o gasto em educação da região metropolitana da cidade do Rio de Janeiro
}

\author{
Marcelo da Silva Machado \\ Pontifícia Universidade Católica do Rio de Janeiro (PUC-RIO), Rio de Janeiro/RJ - Brasil
}

\section{Resumo}

É de conhecimento público que o Brasil passou por diversos períodos autoritários. Para superar o Estado autoritário e centralizador, a Constituição de 1988 elegeu a descentralização como seu principal mote de organização política e administrativa, repassando mais recursos e poder aos governos subnacionais. No campo educacional, tendo os municípios como entes federados, a partir da reforma educacional, implementada na década de 1990, ocorreu o aumento de matrículas do Ensino Fundamental (EF) nas redes municipais e decréscimo nas redes estaduais, sobretudo pós-Fundef. O presente artigo, de natureza quantitativa, tem como objetivo discutir o impacto do federalismo adotado no país e sua repercussão sobre o padrão do financiamento dessa política setorial na região metropolitana da cidade do Rio de Janeiro entre 2008 e 2014.

Palavras-chave: Federalismo. Financiamento da Educação. Ensino Fundamental.

\section{The federative (im)pact and education funding: some approaches over spending in education in the metropolitan region of Rio de Janeiro city}

\begin{abstract}
It is known that Brazil has undergone several authoritarian periods. To overcome the authoritarian and centralizing state, the Constitution of 1988 chose decentralization as its main path for political and administrative organization, transferring more power and resources to subnational governments. From the education reform implemented in the 1990s, there was an increase in elementary school enrollment in municipal networks and a decrease in state networks, especially post-Fundef. This quantitative article aims to discuss the impact of the federalism adopted in the country and its impact on the pattern of funding of this sectoral policy in the metropolitan region of Rio de Janeiro city between 2008 and 2014.
\end{abstract}

Keywords: Federalism. Education Funding. K-12 Education. 
O (im)pacto federativo e financiamento da educação

\section{Introdução}

As mudanças ocorridas no mundo do trabalho na década de 1980 refletiram-se no campo educacional. Como signatário de diversos documentos internacionais, o Brasil assumiu o compromisso de universalizar o acesso à educação obrigatória. Com a Constituição de 1988 (CF/88), a organização político-administrativa do país incluiu o município como ente federado. Assim, a partir do federalismo adotado no país, que pressupõe a colaboração recíproca entre estados e municípios na oferta do ensino fundamental, reiterada pela legislação educacional e incentivada pela implementação do Fundo de Manutenção e Desenvolvimento do Ensino Fundamental e Valorização do Magistério (Fundef), constatou-se, também, o processo de municipalização da educação, que vem se processando tanto no aumento do número de novas matrículas quanto na transferência de estudantes das redes estaduais para as municipais, pari passu à diminuição do número de estabelecimentos, em ambas as redes (LEME; PAREDES; SOUZA, 2009).

O presente artigo tem como tema o pacto federativo e sua repercussão sobre o financiamento da educação na Região Metropolitana da cidade do Rio de Janeiro (RMRJ) entre os anos de 2008 a 2014. A escolha do período é em função da fonte dos dados utilizados, provenientes do Sistema de Informação em Orçamentos Públicos em Educação (SIOPE). Os dados estão disponíveis a partir de 2008 e cerca de $30 \%$ dos municípios do estado $^{1}$ não havia transmitindo as informações relativas a 2015. A opção pela RMRJ se deve a sua importância no estado, abrigando três em cada quatro habitantes.

O SIOPE possui natureza declaratória, compulsória e de responsabilidade do ente federado. Tem por objetivos a constituição de base de dados nacional sobre receitas e investimentos públicos em educação, subsidiar a elaboração de políticas educacionais, assegurar transparência e publicidade às informações sobre financiamento da educação, a produção de indicadores de eficiência e eficácia dos investimentos e instrumentalizar a atuação do controle social (BRASIL, 2008). A periodicidade de envio das informações é anual e o prazo para transmissão dos dados é 30 de abril de cada ano para os municípios, conforme artigo $51 \S 1^{\circ}$, I, da Lei de Responsabilidade Fiscal e 31 de maio para os estados, conforme artigo 51, parágrafo $1^{\circ}$, inciso II da referida lei (BRASIL, 2000).

O texto está organizado em quatro seções, além desta introdução. Na segunda seção o tipo de federalismo adotado no Brasil é discutido e, na sequência, sua repercussão sobre o financiamento. Na quarta seção será apresentado o perfil dos municípios do estado e o padrão de financiamento das redes municipais da RMRJ e, por fim, as considerações finais.

\section{Federalismo}

Sistema político caracterizado por um Estado soberano, composto por diversas entidades territoriais autônomas dotadas de governo próprio. Cunha (2004) destaca que a federação pode ser definida, acima de tudo, como um pacto e um processo permanente de (re)pactuação entre as unidades territoriais e políticas diferentes que escolhem continuar juntas. Conforme Casseb (1999), suas principais características são a existência de Lei

1 Disponível em: <https://www.fnde.gov.br/siope/municipiosTransmitidosPorUF.do?acao=pesquisar\&pag=result \&ano=2015\&periodo=1>. Acesso em: 15 jun. 2016. 
Magna que institua o federalismo como forma de organização do Estado, duas ou mais esferas de governos dotados de autonomia financeira, administrativa e política, além da indissociabilidade dos entes e da repartição de competências.

O funcionamento de uma federação deriva, em boa medida, do próprio sentido etimológico da palavra, do latim foedus, que significa pacto. Antes de uma mera escolha, duas condições levam à sua adoção: (1) existência de heterogeneidades que dividam determinada nação, como grande extensão e/ou enorme diversidade física, linguísticas, étnicas ou socioeconômicas, etc. E, para construir uma nação marcada por tais heterogeneidades, se faz necessária (2) a construção de uma ideologia nacional, alicerçada por instituições que se baseiem no discurso e na prática da unidade na diversidade (ABRUCIO, 2010).

Com a Independência, o Brasil adotou uma forma unitarista com um governo central com grandes poderes sobre as províncias e municípios. Houve a concentração dos tributos no governo central e a escolha dos presidentes de Província era feita pelo imperador (ABRUCIO, 1998). Tal modelo resultou "[...] na manutenção da integridade territorial, num continente marcado pela fragmentação, e nos primeiros passos na construção de um sentimento de nacionalidade" (ABRUCIO, 2010, p. 43). Entretanto, as bases desse modelo eram frágeis, visto que as elites políticas eram basicamente localistas e seus padrões políticos fortemente oligarquizados. Tais elites "[...] só mantiveram o apoio à monarquia enquanto a escravidão existiu - o seu fim precipitou a queda do imperador e da forma unitária de Estado" (ABRUCIO, 2010, p. 43).

Com a República, nasce a federação brasileira, cujo mote principal era o repasse do poder de autogoverno para os estados. É constituído um federalismo baseado em um autonomismo estadual oligárquico, à custa do enfraquecimento dos municípios, das práticas republicanas e do Governo Federal, ampliando a desigualdade territorial, uma das características mais importantes de nossa federação (ABRUCIO, 2010). Para Abrucio (2010), o atraso na adoção de políticas e ações nacionais de bem-estar social e a produção uma enorme heterogeneidade de políticas públicas são características desse modelo.

$\mathrm{Na}$ Era Vargas (1937-1945) o poder torna-se mais centralizado, com o fortalecendo do Executivo Federal e a expansão de ações e de políticas nacionais em várias áreas. Já no Estado Novo, os governos subnacionais tiveram seu poder federativo subtraído e suas máquinas públicas não foram modernizadas para dar conta das crescentes demandas por direitos sociais (ABRUCIO, 2010).

A Constituição de 1946 retoma a autonomia dos estados, concedendo aos municípios a faculdade de autogoverno, assim como a repartição de competência entre os entes federados e eleições regulares. A ditadura militar instaurada em 1964 rompe com o arranjo federativo vigente, dando lugar a outro, mais centralizador.

A CF/88 desenhou nova ordem institucional e federativa. Cury (2010) destaca que a opção em ser uma República Federativa consta em nossa Lei Maior desde o preâmbulo e se repete por 13 vezes. O artigo 60 , parágrafo $4^{\circ}$, inciso I, proíbe, inclusive, qualquer proposta de emenda tendente a abolir a forma federativa do Estado. A federação brasileira é uma cláusula pétrea.

Para Souza (2001), os constituintes de 1988 optaram por duas estratégias principais: a abertura para a participação popular e societal e o compromisso com a descentralização tributária. Da primeira, resulta uma engenharia constitucional em que prevaleceu a busca de 
O (im)pacto federativo e financiamento da educação

consenso e a incorporação das demandas das minorias. A segunda moldou um novo federalismo, descentralizado, tornando-o uma das mais importantes bases da democracia.

É possível afirmar, então, que com a redemocratização, a descentralização emerge como princípio da organização política e administrativa, seja pela garantia constitucional de mais recursos a estados e municípios, seja pela gestão de diversas políticas sociais pelos governos subnacionais ou pelo status de ente federado atribuído aos municípios, fazendo do Brasil "[...] uma das pouquíssimas federações no mundo a dar status de ente federativo aos municípios" (ABRUCIO, 2010, p. 46).

A educação, conforme o artigo $6^{\circ}$ da CF/88 é um direito social, ao lado da saúde, trabalho, moradia, lazer, segurança, dentre outros. De acordo com Oliveira (1999), pela primeira vez na história explicita-se em nossa Constituição a declaração dos direitos sociais, fruto do quadro político-social em que foi elaborada. Uma vez que o direito à educação um direito público subjetivo, o indivíduo tem a possibilidade de transformar a norma geral e abstrata contida no ordenamento jurídico em algo que possua como próprio e, "[...] a maneira de fazê-lo é acionando as normas jurídicas (direito objetivo) e transformando-as em seu direito (direito subjetivo)" (DUARTE, 2004, p. 113).

Uma das formais mais diretas de exercício desse direito é o acesso à escola.

\section{(Im)pacto federativo e o financiamento da educação}

Para Cury (2006), o pacto federativo é um dos fatores mais relevantes para o resultado das políticas educacionais, pois determina a organização e a gestão territorial do estado, com repercussão na estruturação administrativa e política dos governos e na forma como respondem aos cidadãos. Segundo Cruz (2011), o padrão de federalismo desenvolvido no País condiciona e influencia o setor educacional, sobretudo em seu financiamento.

Conforme Farenzena (2010), a responsabilidade pela oferta de educação básica é compartilhada pelos três níveis de governo, com definições dos níveis de atuação prioritária para estados e municípios e da prestação de assistência aos governos subnacionais pela União. Em termos de financiamento, cada esfera de governo possui responsabilidades e prioridades. A partir da Constituição de 1988 e, sobretudo, a partir da política do Fundef, os municípios brasileiros assumiram maior protagonismo na oferta de matrículas públicas, principalmente no ensino fundamental, demonstrando o êxito da política de descentralização.

Entre o início da década de 1970 até meados de 1990, o percentual de matrículas em estabelecimentos educacionais dos municípios brasileiros pouco variou: de 30,53\% em 1971 a 32,96\% em 1996. O quadro se altera significativamente após a implantação do Fundef. Já em 1997, o percentual de atendimento salta para 36,33\%, mantendo constante o crescimento nos anos seguintes. A partir dos anos 2000, pelo menos metade das vagas no ensino fundamental é de responsabilidade municipal, chegando a $56,01 \%$ das vagas em 2014 , conforme Quadro 1: 
O (im)pacto federativo e financiamento da educação

Quadro 1 - Percentual de oferta de matrícula no ensino fundamental no Brasil, por dependência administrativa, 1971 a 2014

\begin{tabular}{|c|c|c|c|c|c|}
\hline Ano & Federal & Estadual & Municipal & Privada & Total \\
\hline 1971-1980 & $0,78 \%$ & $56,90 \%$ & $30,53 \%$ & $11,79 \%$ & $100 \%$ \\
\hline $1981-1989^{3}$ & $0,51 \%$ & $56,06 \%$ & $30,64 \%$ & $12,79 \%$ & $100 \%$ \\
\hline $1991^{4}$ & $0,33 \%$ & $57,47 \%$ & $29,78 \%$ & $12,42 \%$ & $100 \%$ \\
\hline 1992 & $0,11 \%$ & $57,44 \%$ & $30,74 \%$ & $11,71 \%$ & $100 \%$ \\
\hline 1993 & $0,10 \%$ & $57,00 \%$ & $31,46 \%$ & $11,44 \%$ & $100 \%$ \\
\hline 1994 & $0,10 \%$ & $56,67 \%$ & $31,70 \%$ & $11,52 \%$ & $100 \%$ \\
\hline 1995 & $0,10 \%$ & $56,16 \%$ & $32,11 \%$ & $11,63 \%$ & $100 \%$ \\
\hline 1996 & $0,10 \%$ & $55,74 \%$ & $32,96 \%$ & $11,19 \%$ & $100 \%$ \\
\hline 1997 & $0,09 \%$ & $52,87 \%$ & $36,33 \%$ & $10,70 \%$ & $100 \%$ \\
\hline 1998 & $0,08 \%$ & $48,24 \%$ & $42,23 \%$ & $9,45 \%$ & $100 \%$ \\
\hline 1999 & $0,08 \%$ & $46,01 \%$ & $44,83 \%$ & $9,09 \%$ & $100 \%$ \\
\hline 2000 & $0,08 \%$ & $44,25 \%$ & $46,74 \%$ & $8,93 \%$ & $100 \%$ \\
\hline 2001 & $0,08 \%$ & $42,26 \%$ & $48,57 \%$ & $9,09 \%$ & $100 \%$ \\
\hline 2002 & $0,08 \%$ & $40,50 \%$ & $50,22 \%$ & $9,20 \%$ & $100 \%$ \\
\hline 2003 & $0,08 \%$ & $38,54 \%$ & $51,87 \%$ & $9,51 \%$ & $100 \%$ \\
\hline 2004 & $0,07 \%$ & $37,33 \%$ & $52,81 \%$ & $9,79 \%$ & $100 \%$ \\
\hline 2005 & $0,08 \%$ & $36,22 \%$ & $53,64 \%$ & $10,07 \%$ & $100 \%$ \\
\hline 2006 & $0,08 \%$ & $35,53 \%$ & $53,98 \%$ & $10,42 \%$ & $100 \%$ \\
\hline 2007 & $0,08 \%$ & $35,28 \%$ & $54,70 \%$ & $9,94 \%$ & $100 \%$ \\
\hline 2008 & $0,08 \%$ & $34,28 \%$ & $54,36 \%$ & $11,28 \%$ & $100 \%$ \\
\hline 2009 & $0,08 \%$ & $33,35 \%$ & $54,66 \%$ & $11,92 \%$ & $100 \%$ \\
\hline 2010 & $0,08 \%$ & $32,63 \%$ & $54,58 \%$ & $12,71 \%$ & $100 \%$ \\
\hline 2011 & $0,08 \%$ & $31,97 \%$ & $54,44 \%$ & $13,51 \%$ & $100 \%$ \\
\hline 2012 & $0,08 \%$ & $30,58 \%$ & $54,96 \%$ & $14,38 \%$ & $100 \%$ \\
\hline 2013 & $0,08 \%$ & $29,30 \%$ & $55,57 \%$ & $15,05 \%$ & $100 \%$ \\
\hline 2014 & $0,08 \%$ & $28,17 \%$ & $56,01 \%$ & $15,73 \%$ & $100 \%$ \\
\hline
\end{tabular}

Fonte: Araújo (2010) e MEC/INEP - Sinopses do Censo Escolar.

Nas redes estaduais o quadro foi diametralmente oposto. Entre 1971 e 1997, pelo menos $50 \%$ das matrículas no ensino fundamental era de responsabilidade dos estados. Entre 1998 e 2002, esse percentual cai para a casa dos $40 \%$. Desde 2013 , menos de $30 \%$ das vagas nesse nível de ensino são das redes estaduais, fechando 2014 com 28,17\% das vagas.

2 A opção pelo recorte a partir de 1970 se dá por esses dados serem consolidados para todo o $1^{\circ}$ grau, o que confere certa equivalência com o Ensino Fundamental.

3 A edição de 1986 dos Anuários Estatísticos do Brasil não traz os dados de matrícula por dependência administrativa.

4 Em 1990, não foram realizados o Censo Escolar do Inep assim como o Censo Demográfico do IBGE. 
A participação da rede federal na oferta de vagas públicas ao longo do período se manteve inexpressiva, passando de 0,51 em 1971 a 0,08 em 2014.

Pinto (2012, p. 158) adverte que o processo de municipalização avança mais nos anos iniciais, nos quais, em média, $68 \%$ das matrículas pertencem aos municípios, enquanto, nos anos finais, esse índice é de $38 \%$, o que, na visão do autor, aumenta as chances do fracasso escolar, uma vez que "[...] para concluir o ensino fundamental, o aluno tem de percorrer escolas de duas redes distintas, com diferentes padrões de gestão e avaliação".

Conforme Pinto (2012, p. 162), a questão-chave no debate sobre o federalismo e a educação diz respeito aos recursos que os municípios dispõem para gerir suas escolas. Utilizando dados de 2010, o autor mostra que, a cada $\mathrm{R} \$ 100$ arrecadados em tributos no país, o Governo Federal arrecada $R \$ 70$; os estados, $R \$ 25$; e, os municípios, apenas $R \$ 5$ e que, mesmo após as transferências constitucionais previstas "os municípios continuam muito carentes de recursos".

Para Oliveira e Sousa (2010, p. 17), o direito à educação, que pressupõe igualdade de condições para todos, contrapõe-se à diferenciação típica do sistema federativo, o que em nosso país é particularmente importante, pois interfere diretamente nas temáticas da democracia e da igualdade. Para os autores, sob uma perspectiva histórica, nosso arranjo federativo é bastante desigual e se mantém como algo significativo, posto que a divisão dos recursos orçamentários, decorrente da estrutura tributária, não se altera. A situação é agravada com a CF/88 "[...] ao incorporar o município como ente federativo, evidenciando-se descompasso entre os recursos disponibilizados a cada um e suas responsabilidades na oferta educacional, mesmo considerando-se os mecanismos de transferências intergovernamentais".

Entretanto, em nosso ordenamento jurídico já se assentam mecanismos para a redução dessas desigualdades. Uma delas é o regime de colaboração, previsto na CF/88 e na Lei $n^{\circ}$ 9.394/96, que instituiu as Diretrizes e Bases da Educação Nacional (LDB). Para Souza, Ramos e Luiz (2007), a ideia da interdependência e da corresponsabilidade é intrínseca ao federalismo cooperativo no campo educacional, vista que pressupõe o compartilhamento de responsabilidades e encargos educacionais entre os entes federados, uma vez que uma responsabilidade local, em termos de atendimento de vagas, por exemplo, se insere na esfera de responsabilidades do estado e da União, tanto nos aspectos de implementação, coordenação ou avaliação das políticas educacionais, quanto àqueles ligados ao financiamento.

Contudo, a cooperação entre os entes federados prevista na Constituição, na prática, é uma formulação que expressa apenas um desejo (OLIVEIRA; SOUSA, 2010). Sari (2007) coaduna com essa forma de pensar, ao avaliar que, o que fica perceptível nesse contexto, há pouca cooperação efetiva entre essas instâncias de governo, o que propicia o crescimento das desigualdades regionais e a ocorrência de ações superpostas ou omissões.

Outro mecanismo, previsto no artigo 214 da CF/88, diz respeito ao estabelecimento do Sistema Nacional de Educação (SNE). De acordo com o texto constitucional, a lei estabelecerá o Plano Nacional de Educação, de duração decenal, com o objetivo de articular o SNE (BRASIL, 1988). Apesar da recente sanção presidencial da Lei $n^{\circ} 13.005$, de 25 de junho de 2014, aprovando o Plano Nacional de Educação, e deste prever, em seu artigo 13, que o poder público deverá instituir em dois anos, em lei específica, o SNE (BRASIL, 2014), 
O (im)pacto federativo e financiamento da educação

até o momento pouco se avançou nesse sentido. Parafraseando Cara (2012, p. 259), até agora "[...] nenhuma autoridade política, no geral, ou qualquer ministro da Educação, em particular, soube ou quis convocar e liderar a agenda [...]".

Conforme Oliveira e Sousa (2010), à maior descentralização corresponde uma maior desigualdade, a menos que o centro exerça um contrapeso no sentido de implementar ações supletivas. Nos termos de Cruz (2006), as três principais formas de partilha dos recursos da União com os demais entes federados são: salário-educação, programas e projetos implementados pelo Fundo Nacional de Desenvolvimento da Educação (FNDE) e o Fundef, depois o Fundeb.

O parágrafo $5^{\circ}$ do artigo 212 da $\mathrm{CF} / 88$ determina como fonte adicional de recursos 0 Salário-Educação (SE), cuja alíquota de $2,5 \%$ é cobrada sobre o total das remunerações pagas ou creditadas aos empregados das empresas da inciativa privada, ressalvadas as exceções legais. Do total arrecadado, $1 \%$ é destinado à Receita Federal e, do restante, $10 \%$ são destinadas ao FNDE para o financiamento de projetos, programas e ações voltados para a educação básica. O que sobra desse montante é destinado aos entes federados, sob a forma de quotas. A quota federal, correspondente a $1 / 3$ dos recursos, e as cotas estaduais $e$ municipais (2/3) serão distribuídas tendo como base o local em que foi gerada a arrecadação. Assim, na prática, 40,6\% da arrecadação do SE se destina ao governo federal.

Outro mecanismo de aporte de recursos para a educação básica é a assistência financeira da União. Conforme Cruz (2006), a política de assistência a estados e municípios efetivada pelo FNDE envolve ações variadas de assistência direta, como no Programa Nacional do Livro Didático, a assistência financeira automática (Programa Nacional de Alimentação Escolar, Programa Dinheiro Direto na Escola, Programa Nacional de Transporte Escolar, dentre outros) e a assistência financeira por meio de convênios, que dependem de acordos de repasse voluntário mediante a apresentação de projetos.

Outra medida com potencial para reduzir as desigualdades é a política de fundos. Pinto (2012) destaca que o fundamento da proposta que instituiu o Fundef era reduzir as disparidades entre os gastos dos estados e os dos municípios em suas respectivas redes, dentro de uma mesma unidade da federação, e entre as diferentes unidades, por meio do complemento da União. Para Oliveira e Sousa (2010), o Fundef estabeleceu um critério mais razoável para a divisão dos recursos vinculados, de modo a que, minimamente, se articulassem aportes financeiros às respectivas responsabilidades. A complementação da União ao fundo, essencial para a redução das desigualdades, foi reduzida e inconstante e ocorreu apenas nos fundos estaduais do Norte e Nordeste.

O Fundef teve como sucessor o Fundeb. Criado pela Emenda Constitucional $n^{\circ} 53 / 2006$, regulamentado pela Lei $n^{\circ} 11.494 / 2007$ e pelo Decreto $n^{\circ} 6.253 / 2007$, implantado nacionalmente em 2007, elevou gradualmente o percentual da subvinculação das receitas de alguns impostos e transferências constitucionais dos estados, Distrito Federal (DF) e municípios que compõem o novo Fundo de $15 \%$ para $20 \%$ e ampliou o rol de impostos que o compõem, acrescentando, àqueles que compunham o Fundef, o Imposto sobre Propriedade de Veículos Automotores, Imposto Territorial Rural e o Imposto sobre Transmissão Causa Mortis e Doações (BRASIL, 2007).

A base de incidência do novo Fundo considerou uma gradação de percentuais até o patamar de $20 \%$ a partir de 2009. A progressividade também foi observada na 
O (im)pacto federativo e financiamento da educação

complementação da União, alcançado a partir de 2010, 10\% do total de recursos do Fundo. Sua vigência foi fixada em 14 anos (2007 a 2020), mantendo as principais características de seu antecessor. Novamente, a complementação da União, único 'dinheiro novo', ocorrerá apenas quando cada um dos 27 fundos existentes não alcançar o valor mínimo por aluno/ano definido nacionalmente. Apenas os estados do Norte e Nordeste têm recebido a complementação da União, o que do ponto de vista da redução das desigualdades pode ser visto como aspecto positivo.

Contudo, diversos autores argumentam que os ganhos com o novo Fundo serão anulados pela inclusão das demais etapas da educação básica. Militão (2011) destaca que, proporcionalmente, entram mais alunos do que verbas na educação básica, minando o efeito positivo da ampliação dos recursos do fundo. Pinto (2007) destaca que o Fundeb envolve recursos totais $43 \%$ superiores àqueles abrangidos pelo Fundef, mas o número de alunos na educação básica é $61 \%$ superior. Para Davies (2008), o impacto do acréscimo, a partir do terceiro ano, de $5 \%$ dos impostos que compunham o Fundef e de $20 \%$ dos novos impostos, será bastante reduzido ou mesmo anulado pela inclusão das matrículas de educação infantil, Educação de Jovens e Adultos e ensino médio.

Militão (2011) observa que a contribuição financeira do Governo Federal está muito aquém da sua participação na receita tributária nacional, não sendo ainda suficiente para a garantia da universalização de uma educação de qualidade. Por tais razões, concordamos com Araújo (2011) para o qual, após quase três décadas de vigência do modelo federativo promulgado em 1988, as regras de repartição de recursos e responsabilidades não foram devidamente regulamentadas, fazendo com que o regime de colaboração seja impreciso e desequilibrado. Em igual medida, fazemos coro com Cara (2012), para o qual nosso pacto federativo sobrecarrega a esfera municipal, com prejuízos aos seus níveis prioritários de atuação, uma vez que, apesar de serem responsáveis pela educação infantil e pela maioria das vagas no ensino fundamental, possuem menor disponibilidade financeira.

Os dados sobre o dispêndio financeiro dos municípios do estado do Rio de Janeiro, visà-vis à participação da União no esforço em garantir a oferta de vagas em seu nível prioritário de atuação, confirmam tal desequilíbrio.

\section{O estado, seus municípios e gasto em educação}

Com área de 43.780.172 de $\mathrm{km}^{2}$, seus 92 municípios abrigam 16.461.173 habitantes ${ }^{5}$, sendo $12.229 .867(74,30 \%)$ na Região Metropolitana; $882.578(5,36 \%)$ no Norte Fluminense; 820.937 (4,99\%) na Região Serrana; 774.247 (4,70\%) nas Baixadas Litorâneas; 335.686 (2,04\%) no Noroeste Fluminense; 613.283 (3,73\%) no Médio Paraíba; 539.662 (3,28\%) no Centro-Sul Fluminense e $264.913(1,61 \%)$ na Região da Costa Verde.

A maior parte dos municípios ( $n=55$, ou $59,78 \%$ ) tem menos de 50 mil habitantes, concentrando-se, sobretudo, nas regiões Noroeste (13), Serrana (11), Centro-Sul Fluminense (9), Médio Paraíba (7), Norte (6) e Baixadas Litorâneas (5). Os municípios com população entre 50 mil e cem mil habitantes somam-se onze, localizados nas regiões Metropolitana (6), Baixadas Litorâneas (2) e Médio Paraíba (2) e Noroeste (1). Já os municípios com população

5 Disponível em: <http://www.ibge.gov.br/home/estatistica/populacao/estimativa2014/estimativa_tcu.shtm>. Acesso em: 15 jun. 2016. 
entre 100 e 900 mil habitantes totalizam 24 municípios (26\%), a metade na RMRJ. As duas metrópoles, com mais de 900 mil habitantes estão nessa Região, que concentra 21 municípios e cerca de $3 / 4$ da população. Com uma população de $6.453 .682^{6}$, a cidade do Rio de Janeiro abriga $39,20 \%$ da população estadual.

Mapa 1 - Estado do Rio de Janeiro, segundo regiões de Governo

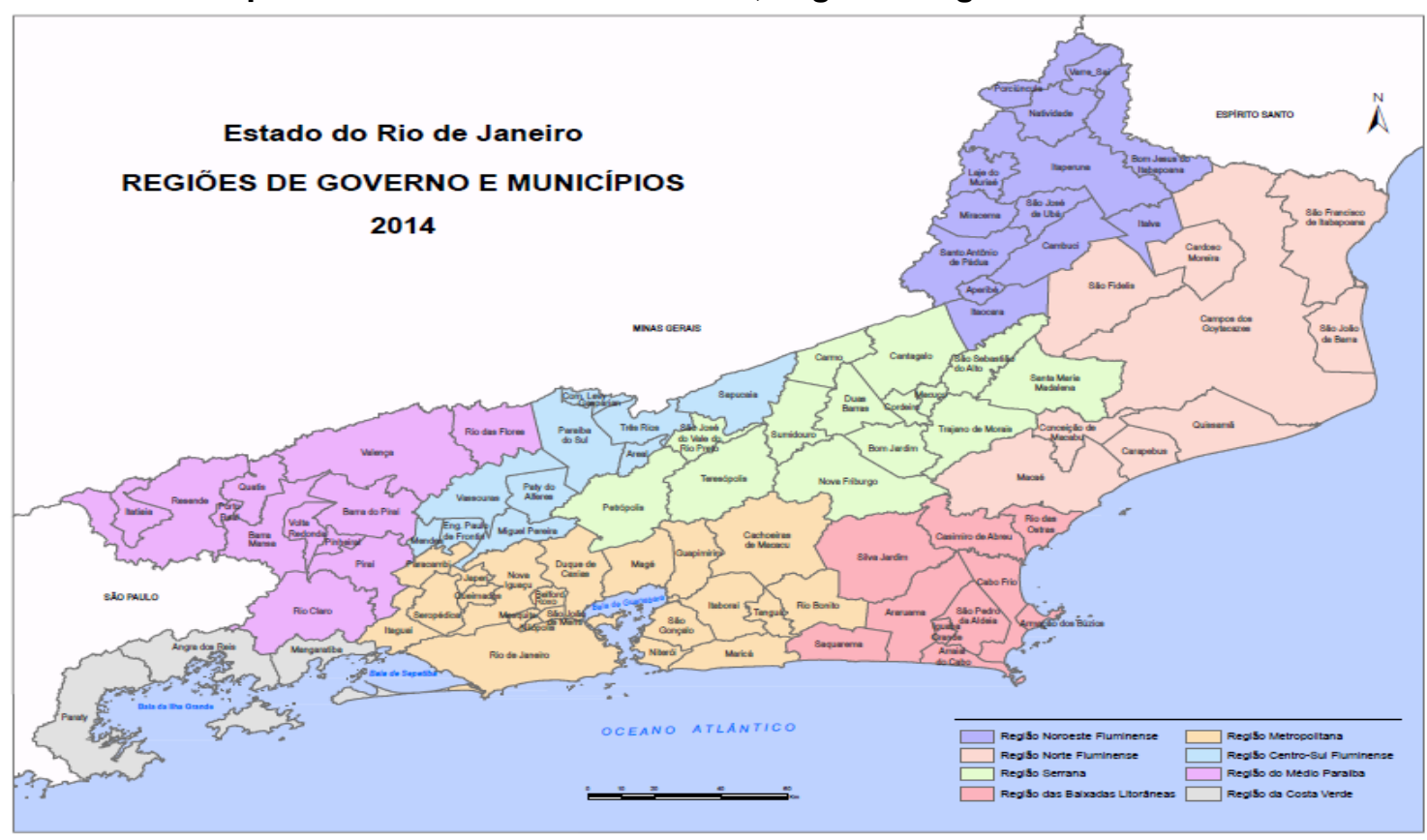

Fonte: Fundação Ceperj $^{7}$ (2014).

\section{Gasto em educação}

Optou-se pela utilização dos indicadores mínimo constitucional, saldo do Fundeb e percentual de recursos provenientes da União via FNDE. Consideramos que estes demonstram o esforço de cada ente federado para o financiamento do nível de ensino de atuação prioritária dos municípios, mas que, conforme previsão legal, deve ocorrer em regime de colaboração. É importante destacar que tanto os recursos do Fundeb quantos os do FNDE são acréscimos aos gastos em manutenção e desenvolvimento do ensino (MDE).

De acordo com Davies (2012), a vinculação de impostos é o aspecto mais importante na discussão sobre o financiamento da educação pública. Conforme o artigo 212 da CF/88, os municípios devem investir, no mínimo, $25 \%$ da receita resultante de impostos, compreendida a proveniente de transferências em MDE.

A maior parte dos gastos dos municípios foi com o ensino fundamental, média de $80,40 \%$. A menor proporção de gasto com esse nível foi em São João de Meriti $(69,85 \%)$, seguido por Rio Bonito $(75,36 \%)$, Niterói $(75,60 \%)$, Tanguá $(77,16 \%)$ e Mesquita $(77,71 \%)$. Também aplicaram recursos no ensino fundamental abaixo da média regional Duque de Caxias $(78,24 \%)$, Maricá $(79,01 \%)$, Magé $(79,26 \%)$ e Paracambi $(79,85 \%)$. As maiores médias de gastos com ensino

6 Disponível em: <http://www.ibge.gov.br/home/estatistica/populacao/estimativa2014/estimativa_tcu.shtm>. Acesso em: 15 jun. 2016.

7 Disponível em: <http://www.ceperj.rj.gov.br/ceep/info_territorios/divis_regional.html>. Acesso em: 15 jun. 2016. 
fundamental, no período analisado, foram registradas em Cachoeiras de Macacu (84,88\%), Rio de Janeiro (84,38\%), Queimados (84,36\%), Guapimirim (83,49\%) e Itaboraí (83,38\%).

O Quadro 2 traz as informações relativas ao percentual de receitas vinculadas, as médias e o percentual determinado nas leis orgânicas dos municípios da RMRJ:

Quadro 2 - Mínimo constitucional aplicado em MDE, média do período e vinculação prevista nas leis orgânicas, municípios RMRJ, 2008 a 2014 (\%)

\begin{tabular}{|c|c|c|c|c|c|c|c|c|c|}
\hline Município & 2008 & 2009 & 2010 & 2011 & 2012 & 2013 & 2014 & Média & LO \\
\hline Belford Roxo & 30,34 & 27,67 & 25,75 & 27,86 & 26,33 & 25,61 & 26,01 & 27,08 & 25 \\
\hline Cachoeiras de Macacu & 33,53 & 26,62 & 33,37 & 30,79 & 34,83 & 34,57 & 34,96 & 32,67 & 35 \\
\hline Duque de Caxias & 34,38 & 33,87 & 30,86 & 32,16 & 33,89 & 36 & 35,94 & 33,87 & 35 \\
\hline Guapimirim & 30,12 & 24,78 & 26,99 & 28,57 & 24,66 & 25 & 34,76 & 27,84 & 25 \\
\hline Itaboraí & 25,66 & 25,21 & 26,23 & 27,07 & 25,93 & 25,16 & 27,05 & 26,04 & 25 \\
\hline Itaguaí & 27,15 & 29,5 & 25 & 27,52 & 29,56 & 29,61 & 34,61 & 28,99 & 25 \\
\hline Japeri & 25,3 & 26,8 & 25,97 & 29,66 & 28,67 & 26,83 & 28,95 & 27,45 & 25 \\
\hline Magé & 25,17 & 28,48 & 27,86 & 27,53 & 22,87 & 26,03 & 28,09 & 26,58 & 25 \\
\hline Maricá & 25,51 & 25,25 & 27,64 & 25,15 & 29,4 & 25,71 & 25,62 & 26,33 & 30 \\
\hline Mesquita & 21,73 & 25,54 & 28,75 & 26,9 & 29,35 & 30,96 & 33,42 & 28,09 & $25^{*}$ \\
\hline Nilópolis & 25,07 & 25,65 & 26,04 & 28,1 & 25,45 & 25,43 & 26,28 & 26,00 & 25 \\
\hline Niterói & 27,79 & 26,56 & 25,36 & 24,21 & 25,12 & 26,71 & 27,02 & 26,11 & 25 \\
\hline Nova Iguaçu & 25,79 & 25,14 & 26,22 & 31,88 & 29,35 & 26,46 & 26,12 & 27,28 & 25 \\
\hline Paracambi & 30,71 & 28,57 & 24,24 & 30,04 & 29,24 & 35,45 & 30,03 & 29,75 & 25 \\
\hline Queimados & 25,04 & 27,54 & 32,23 & 25,08 & 26,82 & 26,17 & 27,4 & 27,18 & 25 \\
\hline Rio Bonito & 30,02 & 25,14 & 26,58 & 26,87 & 33,68 & 29,92 & 25,56 & 28,25 & 25 \\
\hline Rio de Janeiro & 26,74 & 25,64 & 24,41 & 25,3 & 25,67 & 25,4 & 25,42 & 25,51 & 25 \\
\hline São Gonçalo & 26,62 & 26,61 & 25,02 & 25,08 & 27,13 & 26,59 & 25,44 & 26,07 & 25 \\
\hline São João de Meriti & 25,08 & 26,97 & 34,94 & 35,85 & 35,9 & 31,34 & 25,89 & 30,85 & 25 \\
\hline Seropédica & 35,75 & 30,61 & 27,56 & 34,5 & 31,22 & 35,77 & 35,58 & 33,00 & 25 \\
\hline Tanguá & 28,67 & 29,97 & 33,71 & 32,72 & 33,4 & 28,87 & 29,67 & 31,00 & 25 \\
\hline Média estadual & 28,89 & 29,12 & 28,81 & 29,15 & 29,33 & 28,78 & 29,24 & & \\
\hline
\end{tabular}

Fonte: Elaboração do autor a partir dos dados do SIOPE.

* Não determina percentual mínimo.

Algumas leis orgânicas (LO) ampliaram esse percentual. Dos 21 municípios da RMRJ, apenas Maricá (30\%), Cachoeiras de Macacu (35\%) e Duque de Caxias (35\%) determinaram percentuais superiores. Contudo, apenas Duque de Caxias, em 2013 e 2014, cumpriu sua legislação. Nas três municipalidades, a média do percentual vinculado foi menor do que o previsto.

A cidade do Rio de Janeiro é o principal centro produtor e distribuidor de bens e serviços de todo o estado 8 . Contudo, foi quem menos vinculou recursos, na média, no período analisado, seguida por Nilópolis, Itaboraí, Mesquita, São Gonçalo e Niterói. Dentre os municípios da RMRJ que mais vincularam recursos, na média, em MDE, encontra-se Duque de Caxias $(33,87)$, Seropédica $(33,00)$, Cachoeiras de Macacu $(32,67)$, Tanguá $(31,00)$ e São

8 Fundação Ceperj, vinculada à Secretaria de Estado de Planejamento e Gestão. Disponível em: <http://www.ceperj.rj.gov.br/ceep/info_territorios/divis_regional.html>. Acesso em: 09 jun. 2016. 
João de Meriti $(30,85)$. Na outra ponta, Mesquita (2008, 21,73\%), Guapimirim (2009, 24,75\%), Paracambi (2010, 24,24\%), Niterói (2011, 24,61\%) e Guapimirim e Magé (2012, 24,66\% e $22,87 \%$, respectivamente) foram os municípios que aplicaram percentuais abaixo da previsão constitucional.

Em relação ao gasto por aluno do ensino fundamental o panorama foi:

\section{Quadro 3 - Gasto por aluno, média de gasto (em R\$) e variação do gasto (\%), municípios} RMRJ, 2008 a 2014

\begin{tabular}{|c|c|c|c|c|c|c|c|c|c|}
\hline Município & 2008 & 2009 & 2010 & 2011 & 2012 & 2013 & 2014 & Média & Variação \\
\hline Belford Roxo & $1.973,17$ & $2.100,24$ & $2.750,61$ & $3.225,36$ & $3.410,20$ & $4.481,12$ & $4.476,82$ & $3.202,50$ & 126,88 \\
\hline $\begin{array}{c}\text { Cachoeiras de } \\
\text { Macacu }\end{array}$ & $5.864,59$ & $3.954,52$ & $7.523,09$ & $4.901,11$ & $6.266,56$ & $7.999,43$ & $7.403,36$ & $6.273,24$ & 26,24 \\
\hline Duque de Caxias & $3.015,38$ & $3.761,86$ & $5.021,92$ & $5.572,21$ & $7.075,21$ & $7.823,37$ & $7.888,27$ & $5.736,89$ & 161,60 \\
\hline Guapimirim & $3.879,49$ & $3.118,05$ & $4.361,08$ & $5.024,69$ & $4.410,60$ & $4.821,76$ & $5.973,71$ & $4.512,77$ & 53,98 \\
\hline Itaboraí & $1.973,72$ & $2.260,86$ & $3.050,69$ & $4.126,70$ & $5.365,30$ & $6.705,05$ & $6.860,84$ & $4.334,74$ & 247,61 \\
\hline Itaguaí & $3.557,05$ & $4.003,81$ & $4.801,85$ & $6.521,22$ & $7.946,49$ & $8.185,02$ & $10.926,94$ & $6.563,20$ & 207,19 \\
\hline Japeri & $1.938,42$ & $2.263,44$ & $2.594,18$ & $3.466,74$ & $3.499,33$ & $3.913,93$ & $4.549,66$ & $3.175,10$ & 134,71 \\
\hline Magé & $2.046,05$ & $2.488,24$ & $3.005,43$ & $3.395,01$ & $3.022,99$ & $3.718,51$ & $4.304,99$ & $3.140,17$ & 110,40 \\
\hline Maricá & $2.518,96$ & $2.784,56$ & $3.937,20$ & $4.025,92$ & $4.793,35$ & $5.102,39$ & $6.858,73$ & $4.583,69$ & 172,28 \\
\hline Mesquita & $1.896,08$ & $2.486,98$ & $3.401,11$ & $4.243,02$ & $4.995,47$ & $5.569,90$ & $6.223,92$ & $4.116,64$ & 228,25 \\
\hline Nilópolis & $2.805,60$ & $3.015,13$ & $3.399,28$ & $4.265,19$ & $4.120,93$ & $4.754,39$ & $4.625,58$ & $3.855,16$ & 64,87 \\
\hline Niterói & $2.579,53$ & $1.956,56$ & $8.241,33$ & $8.631,23$ & $9.574,56$ & $10.770,25$ & $11.144,31$ & $7.556,82$ & 332,03 \\
\hline Nova Iguaçu & $2.324,82$ & $2.759,84$ & $3.479,34$ & $4.617,02$ & $4.475,01$ & $5.250,63$ & $5.611,32$ & $4.074,00$ & 141,37 \\
\hline Paracambi & $2.628,43$ & $2.666,42$ & $3.219,59$ & $3.782,98$ & $4.221,85$ & $5.472,89$ & $6.138,86$ & $4.018,72$ & 133,56 \\
\hline Queimados & $6.310,75$ & $5.302,80$ & $7.089,66$ & $8.566,11$ & $9.380,87$ & $10.169,50$ & $12.591,67$ & $8.487,34$ & 99,53 \\
\hline Rio Bonito & $3.661,35$ & $3.283,27$ & $3.976,99$ & $3.746,61$ & $5.001,47$ & $6.134,58$ & $6.948,71$ & $4.679,00$ & 89,79 \\
\hline Rio de Janeiro & $4.019,80$ & $4.222,99$ & $4.913,01$ & $5.991,51$ & $6.820,80$ & $8.242,10$ & $8.554,04$ & $6.109,18$ & 112,80 \\
\hline São Gonçalo & $2.458,52$ & $2.829,75$ & $3.379,19$ & $4.677,56$ & $4.815,72$ & $5.628,91$ & $5.156,05$ & $4.135,10$ & 109,72 \\
\hline São João de Meriti & $1.721,13$ & $2.522,96$ & $2.846,39$ & $4.348,80$ & $4.815,82$ & $5.948,10$ & $8.224,48$ & $4.346,81$ & 377,85 \\
\hline Seropédica & $2.545,10$ & $2.588,21$ & $3.277,61$ & $4.021,47$ & $3.961,35$ & $5.519,61$ & $6.161,16$ & $4.010,64$ & 142,08 \\
\hline Tanguá & $2.460,02$ & $2.677,67$ & $3.086,75$ & $3.709,82$ & $3.825,57$ & $3.988,19$ & $4.948,99$ & $3.528,14$ & 101,18 \\
\hline Média estadual & $3.379,70$ & $3.707,55$ & $4.560,78$ & $4.987,24$ & $5.465,84$ & $6.163,96$ & $6.900,12$ & $5.017,09$ & 104,16 \\
\hline
\end{tabular}

Fonte: Elaboração do autor a partir dos dados do SIOPE.

O gasto médio per capita da RMRJ no período analisado foi de $\mathrm{R} \$ 4.768,80$, valor menor do que a média estadual, que foi de pouco mais de 5 mil reais. Os gastos médios mais elevados foram registrados em Queimados $(R \$ 8.487,34)$, Niterói $(R \$ 7.556,82)$ e Itaguaí $(R \$$ $6.563,20)$. As menores médias foram as de Magé $(R \$ 3.140,17)$, Japeri $(R \$ 3.175,10)$ e Belford Roxo (R\$3.202,50). Em 15 redes ou $71,42 \%$ dos municípios da Região, o gasto médio por aluno foi menor do que a média estadual, indicando os desafios dessas municipalidades em gerir seus respectivos sistemas educacionais. Já as maiores variações foram encontradas em São João de Meriti $(337,85 \%)$, Niterói $(332,03 \%)$ e Itaboraí $(247,61 \%)$ e, as menores, em Cachoeiras de Macacu (26,24\%), Guapimirim (53,98\%) e Nilópolis $(64,87 \%)$. A variação do 
O (im)pacto federativo e financiamento da educação

Índice Geral de Preços do Mercado (IGPM), utilizado no presente estudo para corrigir os valores praticados, foi de 40,34\% entre 2008 e 2014.

Sobre o Fundeb, cumpre destacar que estados e municípios aportam e recebem recursos. Nem sempre o saldo é positivo, mas para as cidades da RMRJ a conta tem sido favorável:

Quadro 4 - Saldo acumulado após o aporte e recebimento de recursos Fundeb, 2008 a 2014 (em R\$)

\begin{tabular}{|c|c|c|}
\hline MUNICÍPIO & \multicolumn{2}{|c|}{ ACUMULADO } \\
\hline Rio de Janeiro & $\mathrm{R} \$$ & 7.807.624.042,53 \\
\hline Nova Iguaçu & $\mathrm{R} \$$ & $855.598 .679,90$ \\
\hline Belford Roxo & $\mathrm{R} \$$ & $597.947 .645,89$ \\
\hline São Gonçalo & $\mathrm{R} \$$ & $495.667 .266,77$ \\
\hline Duque de Caxias & $\mathrm{R} \$$ & $480.234 .541,06$ \\
\hline Magé & $\mathrm{R} \$$ & $410.960 .260,24$ \\
\hline Itaboraí & $\mathrm{R} \$$ & $380.011 .529,34$ \\
\hline São João de Meriti & $\mathrm{R} \$$ & $277.573 .519,30$ \\
\hline Itaguaí & $\mathrm{R} \$$ & $190.479 .451,55$ \\
\hline Seropédica & $\mathrm{R} \$$ & $187.078 .463,92$ \\
\hline Japeri & $\mathrm{R} \$$ & $181.514 .474,90$ \\
\hline Maricá & $\mathrm{R} \$$ & $143.713 .259,32$ \\
\hline Queimados & $\mathrm{R} \$$ & $130.428 .512,93$ \\
\hline Mesquita & $\mathrm{R} \$$ & $121.262 .167,50$ \\
\hline Nilópolis & $\mathrm{R} \$$ & $81.625 .917,67$ \\
\hline Rio Bonito & $\mathrm{R} \$$ & $81.295 .120,56$ \\
\hline Guapimirim & $\mathrm{R} \$$ & $56.742 .686,12$ \\
\hline Paracambi & $\mathrm{R} \$$ & $43.607 .628,57$ \\
\hline Tanguá & $\mathrm{R} \$$ & $38.284 .260,98$ \\
\hline Niterói & $\mathrm{R} \$$ & $34.790 .984,97$ \\
\hline Cachoeiras de Macacu & $\mathrm{R} \$$ & $30.450 .983,30$ \\
\hline
\end{tabular}

Fonte: Elaboração do autor a partir dos dados do SIOPE.

Todos os municípios da Região recebem recursos adicionais via Fundeb. Como não há complementação da União, são os outros municípios do estado e o próprio Governo estadual que 'perdem' tais recursos. Aliás, a única contribuição financeira do estado para seus municípios tem sido via mecanismos de transferência do Fundeb, algo em torno de $R \$ 16,5$ bilhões. O problema é que outros municípios do estado ajudam a pagar essa conta. De acordo com Machado (2015), 28 municípios fluminenses perderam recursos ao longo da vigência do Fundo. Justiça redistributiva? Talvez não.

Como foram mantidos os critérios para o aporte e recebimento dos recursos e, como assinalado por Bremaeker (2003), mesmo que um município seja responsável por $100 \%$ das matrículas em seu território, essa lógica faz com que os pequenos municípios sejam penalizados. Dentre os perdedores, apenas Angra dos Reis e Macaé possuem mais de 100 mil habitantes e dinamismo econômico por conta da indústria energética, nuclear e petrolífera. 
O (im)pacto federativo e financiamento da educação

Os demais municípios, 20 deles com menos de 20 mil habitantes $^{9}$, pertencem às regiões do estado com baixa atividade econômica, a maioria dependentes do Fundo de Participação dos Municípios (MACHADO, 2015).

Por fim, serão apresentados os percentuais de recursos advindos da União. Nos termos de Cruz (2006), os projetos e programas do FNDE têm um papel altamente indutor na implementação, em âmbito local, da política nacional de educação. Contudo, mesmo considerando a expectativa, a se fazer cumprir, de que tais recursos combatam as desigualdades, concordamos com os argumentos de Cruz (2009), segundo os quais, ainda que haja indícios dessa preocupação nos critérios definidos pelos programas, sua efetivação ainda é insuficiente.

As informações do Quadro 5 mostram como são baixos, em relação ao total das receitas, os repasses federais para a educação dos municípios da RMRJ. É importante assinalar que, apesar de relativamente baixos, tais recursos são importantes, muito em função da pouca disponibilidade de recursos para os municípios, um indício de que melhorias no cenário atual passam, necessariamente, pela maior participação da União no financiamento da educação básica e, em especial, do ensino fundamental.

Quadro 5 - Percentuais e média de recursos FNDE recebidos pelos municípios da RMRJ, 2008 a 2014

\begin{tabular}{|c|c|c|c|c|c|c|c|c|}
\hline MUNICÍPIO & 2008 & 2009 & 2010 & 2011 & 2012 & 2013 & 2014 & MÉDIA \\
\hline Niterói & 0,78 & 0,72 & 0,9 & 0,86 & 0,86 & 0,86 & 0,95 & 0,85 \\
\hline Rio de Janeiro & 1,97 & 1,98 & 2,2 & 1,84 & 1,97 & 1,97 & 2,12 & 2,01 \\
\hline Cachoeiras de Macacu & 2,22 & 1,81 & 1,83 & 2,08 & 3,1 & 2,37 & 2,45 & 2,27 \\
\hline Itaguaí & 2,36 & 2,92 & 2,2 & 2,22 & 2,2 & 2,57 & 3,15 & 2,52 \\
\hline Maricá & 2,6 & 2,67 & 3,22 & 2,28 & 2,63 & 2,39 & 2,02 & 2,54 \\
\hline Duque de Caxias & 2,02 & 2,5 & 3,27 & 2,3 & 2,8 & 2,81 & 2,54 & 2,61 \\
\hline Paracambi & 2,12 & 2,45 & 2,33 & 2,6 & 2,78 & 3,07 & 3,26 & 2,66 \\
\hline Nilópolis & 2,24 & 2,56 & 2,49 & 2,4 & 2,54 & 4,33 & 2,7 & 2,75 \\
\hline Rio Bonito & 2,04 & 3,74 & 2,94 & 2,73 & 2,71 & 2,36 & 2,77 & 2,76 \\
\hline Guapimirim & 2,12 & 2,59 & 2,89 & 2,96 & 3,28 & 3,26 & 3,69 & 2,97 \\
\hline São Gonçalo & 3,86 & 2,91 & 3,33 & 3,7 & 2,64 & 3,24 & 2,94 & 3,23 \\
\hline Mesquita & 2,6 & 3,27 & 3,3 & 3,66 & 3,7 & 3,36 & 4,58 & 3,50 \\
\hline Queimados & 3,26 & 3,86 & 4,69 & 4,85 & 3,25 & 3,55 & 3,89 & 3,91 \\
\hline Tanguá & 4,34 & 3,35 & 4,26 & 3,23 & 3,62 & 5,03 & 4,21 & 4,01 \\
\hline São João de Meriti & 3,43 & 3,27 & 4,02 & 4,72 & 4,86 & 4,46 & 3,67 & 4,06 \\
\hline Nova Iguaçu & 3,57 & 2,86 & 3,55 & 5,42 & 4,53 & 4,78 & 5,58 & 4,33 \\
\hline Itaboraí & 3,56 & 5 & 3,4 & 9,94 & 4,68 & 3,51 & 2,96 & 4,72 \\
\hline Seropédica & 4,18 & 4,82 & 4,73 & 5,14 & 5,43 & 4,37 & 5,05 & 4,82 \\
\hline Belford Roxo & 4,54 & 4,63 & 5,28 & 5,2 & 6,06 & 5,09 & 5,76 & 5,22 \\
\hline Japeri & 4,14 & 4,51 & 4,93 & 5,98 & 6,17 & 5,46 & 5,73 & 5,27 \\
\hline Magé & 5,82 & 5,98 & 7,43 & 5,31 & 5,82 & 5,45 & 5,70 & 5,93 \\
\hline MEDIA REGIONAL & & & & & & & & 3,47 \\
\hline
\end{tabular}

Fonte: Elaboração do autor a partir dos dados do SIOPE.

9 Disponível em: <http://www.ibge.gov.br/home/estatistica/populacao/estimativa2014/estimativa_tcu.shtm>. Acesso em: 09 jun. 2016. 
Em Magé foram encontradas a maior participação de recursos do FNDE na receita, com uma média de 5,93\% no período, seguido por Japeri e Belford Roxo. Tais municípios apresentam baixos valores de arrecadação própria. Os menores percentuais foram encontrados justamente naqueles municípios com as economias mais dinâmicas. À primeira vista, a questão pode ser indicadora de que os recursos federais se destinam aos municípios com menores recursos. Contudo, os municípios do Rio de Janeiro e Niterói receberam os maiores repasses em valores absolutos. Tal aparente contradição expõe uma realidade em que a colaboração é bastante reduzida.

\section{Considerações Finais}

Desde a Constituição de 1988, passando pela aprovação da LDB e políticas de fundos, os municípios brasileiros passaram a responder pela maioria de matrículas no ensino fundamental e a quase totalidade na educação Infantil, muitas vezes acima de suas capacidades econômicas. Além da vinculação de impostos, a CF determina, como fonte adicional de recursos, o salário educação. Com a recente política de fundos instituída em nosso país, alguns entes federados poderão obter recursos adicionais, outros perderão ${ }^{10}$. Contudo, tal engenharia não tem sido suficiente para prover uma educação com qualidade.

A maior parte dos recursos vinculados e do Fundeb estão comprometidos com a folha de pagamento. Somados a outras despesas com custeio (conta de luz, mobiliário e a precária manutenção dos prédios, dentre outros), é reduzida a capacidade de investimento dos municípios, com prejuízos à infraestrutura das escolas, materiais pedagógicos e equipamentos. Enfim, prejuízos à aprendizagem. Urge repensar nosso arranjo institucional em relação à política educacional. Os dados referentes ao mínimo constitucional e gasto por aluno da RMRJ indicam que a capacidade desses entes federados se encontra no limite.

A questão torna-se ainda mais relevante quando se percebe que o ente federado que mais arrecada é aquele que tem a menor responsabilidade com o ensino fundamental. Segundo informações do Conselho de Desenvolvimento Econômico da Presidência da República, em 2010 a União reteve $57,1 \%$ dos recursos financeiros, ficando $24,6 \%$ para os 26 estados e DF e os outros $18,3 \%$ divididos entre os mais de 5.570 municípios. Porém, em 2009, de acordo com dados do Instituto Nacional de Estudos e Pesquisas Educacionais Anísio Teixeira, a cada $R \$ 1,00$ investido em políticas educacionais, estados e o DF gastaram $R \$$ 0,41, os municípios $R \$ 0,39$ e a União apenas $R \$ 0,20$ (CARA, 2012).

\section{Referências}

ABRUCIO, Fernando Luiz. Os barões da Federação: os governadores e a redemocratização brasileira. São Paulo: Hucitec, 1998.

ABRUCIO, Fernando Luiz. A dinâmica federativa da educação brasileira: diagnóstico e propostas de aperfeiçoamento. In: OLIVEIRA, Romualdo Portela de; SANTANA, Wagner (Org.). Educação e federalismo no Brasil: combater as desigualdades, garantir a diversidade. Brasília: UNESCO, 2010. p. 39-70.

10 A este respeito ver Machado (2015). 
O (im)pacto federativo e financiamento da educação

ARAUJO, Gilda Cardoso de. Evolução das matrículas na etapa elementar de escolarização no Brasil de 1932 a 2003. Revista Brasileira de Estudos Pedagógicos, Brasília, v. 91, n. 227, p. 29-54, 2010.

ARAÚJO, R. L. S. O federalismo brasileiro e a aprovação da Emenda Constitucional $n^{\circ} 53$, de 2006. Fineduca - Revista de Financiamento da Educação, Porto Alegre; São Paulo, v. 1, n. 5, p. 1-13, 2011. Disponível em: <http://seer.ufrgs.br/fieduca>. Acesso em: 05 jun. 2016.

BELFORD ROXO. Lei Orgânica de Belford Roxo, de 13 de agosto de 1993. Disponível em: <http://prefeiturabelfordroxo.com.br/wp-content/uploads/2015/09/Lei-Org\%C3\%A2nicaMunicipal-atualizada-at\%C3\%A9-emenda-31.06.doc.pdf>. Acesso em: 01 jun. 2016.

BRASIL. Constituição da República Federativa do Brasil, promulgada em 05 de Outubro de 1988. Constituição da República Federativa do Brasil de 1988. Diário Oficial da República Federativa do Brasil, Brasília, DF, 05 out. 1988. Disponível em: <http://www.planalto.gov.br/ccivil_03/constituicao/ConstituicaoCompilado.htm>. Acesso em: 12 out. 2014.

BRASIL. Instituto Nacional de Estudos e Pesquisas Educacionais Anísio Teixeira - INEP. Ministério da Educação. Sinopses do Censo Escolar. Disponível em: <http://portal.inep.gov.br/basica-censo-escolar-sinopse-sinopse>. Acesso em: 15 jun. 2015.

BRASIL. Lei de Diretrizes e Bases da Educação Nacional, de 20 de Dezembro de 1996. Estabelece as diretrizes e bases da educação nacional. Diário Oficial da União, Brasília, DF, 20 de dez. 1996. Disponível em: <http://www.planalto.gov.br/ccivil_03/LEIS//9394.htm>. Acesso em: 19 dez. 2014.

BRASIL. Lei Complementar N N 101, de 04 de Maio de 2000. Estabelece normas de finanças públicas voltadas para a responsabilidade na gestão fiscal e dá outras providências. Diário Oficial da União, Brasília, DF, 04 de maio 2000. Disponível em: <http://www.planalto.gov.br/ccivil_03/leis/lcp/lcp101.htm>. Acesso em: 23 dez. 2014.

BRASIL. Lei $n^{\circ}$ 11.494, de 20 de junho de 2007. Regulamenta o Fundo de Manutenção e Desenvolvimento da Educação Básica e de Valorização dos Profissionais da Educação Fundeb, que trata o art. 60 do Ato das Disposições Constitucionais Transitórias e dá outras providências. Diário Oficial da União, Brasília, DF, 20 jun. 2007. Disponível em: <http://www.planalto.gov.br/ccivil_03/_ato2007-2010/2007/lei//11494.htm>. Acesso em: 05 jun. 2015.

BRASIL. Lei no 13.005, de 25 de junho de 2014. Aprova o Plano Nacional de Educação - PNE e dá outras providências. Diário Oficial da União, Brasília, DF, 25 de jun. 2014. Disponível em: <http://www.planalto.gov.br/ccivil_03/_ato2011-2014/2014/lei/l13005.htm>. Acesso em: 05 jun. 2016

BRASIL. Emenda Constitucional n 14, de 12 de setembro de 1996. Dá nova aos artigos 34 , 208, 211 e 212 da Constituição Federal e dá nova redação ao artigo 60 do Ato das Disposições Constitucionais Transitórias. Diário Oficial da União, Brasília, DF, 12 de set. 1996. Disponível em: <http://www.planalto.gov.br>. Acesso em: 23 out. 2014.

BRASIL. Emenda Constitucional $n^{\circ} 53$, de 20 de dezembro de 2006. Dá nova redação aos artigos 7, 223, 30, 206, 208, 211 e 212 da Constituição Federal e dá nova redação ao artigo 
60 do Ato das Disposições Constitucionais Transitórias. Diário Oficial da União, Brasília, DF, 20 de dez. 2006. Disponível em: <http://www.planalto.gov.br/ccivil_03/constituicao/Emendas/ Emc/emc53.htm>. Acesso em: 19 dez. 2007.

BRASIL. Ministério da Educação. Portaria $n^{\circ}$ 844, de 8 de julho de 2008. Define os objetivos do SIOPE. Brasília, DF, 09 de jul. 2008. Disponível em $<$ http://www.fnde.gov.br/fnde/legislacao/portarias/item/3564-portaria-mec-n\%C2\%BA-844de-08-de-julho-de-2008>. Acesso em 15 out. 2015.

BREMAEKER, François E. J. A influência do Fundef nas finanças municipais em 2002. Série Estudos Especiais, n. 59. Rio de Janeiro: Instituto Brasileiro de Administração Municipal, 2003.

CACHOEIRAS DE MACACU. Lei Orgânica de Cachoeiras de Macacu, de 05 de abril de 1990. Disponível em: <http://camaracachoeirasdemacacu.rj.gov.br/Legislacao/Lei_Organica.htm>. Acesso em jun.2016.

CARA, Daniel. Municípios no pacto federativo: Fragilidades sobrepostas. Retratos da Escola, Brasília, v. 6, n. 10, p. 255-273, 2012.

CASSEB, Paulo Adib. Federalismo: aspectos contemporâneos. São Paulo: Juarez de Oliveira, 1999. (Coleção Saber Jurídico).

CRUZ, Rosana Evangelista da. Relações federativas e o financiamento da educação. Eccos: Revista

Científica, São Paulo, v. 8, n. 1, p. 47-64, 2006.

CRUZ, Rosana Evangelista da. Pacto federativo e financiamento da educação: a função supletiva e redistributiva da União - o FNDE em destaque. 2009. 434 f. Tese (Doutorado em Educação) - Faculdade de Educação, Universidade de São Paulo, São Paulo, 2009.

CRUZ, Rosana Evangelista da. Federalismo e financiamento da educação: a política do FNDE. In: GOUVEIA, Andréa Barbosa; PINTO, José Marcelino de Rezende; CORBUCCI, Paulo Roberto (Org.). Federalismo e políticas educacionais na efetivação do direito à educação no Brasil. Brasília: IPEA, 2011. p. 78-94.

CRUZ, Rosana Evangelista da. Federalismo e relações intergovernamentais: os consórcios públicos como instrumento de cooperação federativa. Revista do Serviço Público, Brasília, n. 3, p. 5-36, 2004.

CURY, Carlos Roberto Jamil. Federalismo político e educacional. In: FERREIRA, Naura Syria Carapeto (Org.). Políticas públicas e gestão da educação: polêmicas, fundamentos e análises. Brasília, DF: Líber Livro, 2006.

CURY, Carlos Roberto Jamil. A questão federativa e a educação escolar. In: OLIVEIRA, Romualdo Portela de; SANTANA, Wagner (Org.). Educação e federalismo no Brasil: combater as desigualdades, garantir a diversidade. Brasília: UNESCO, 2010. p. 149-168.

DAVIES, Nicholas. Fundeb: a redenção da educação básica? Campinas: Autores Associados, 2008.

DAVIES, Nicholas. O Financiamento da Educação Estatal no Brasil: novos ou velhos desafios? Revista Educação On-line PUC-Rio, Rio de Janeiro, n. 10, p. 31-63, 2012. 
O (im)pacto federativo e financiamento da educação

DUARTE, Clarice Seixas. Direito Público subjetivo e Políticas Educacionais. São Paulo em Perspectiva, São Paulo, v. 18, n. 2, p. 113-118. 2004. Disponível em: $<$ http://www.scielo.br/scielo.php?script=sci_arttext\&pid=S010288392004000200012\&Ing=en \&nrm=iso>. Acesso em: 07 out. 2014.

DUQUE DE CAXIAS. Lei Orgânica de Duque de Caxias, de 05 de abril de 1990. Disponível em: <http://www.cmdc.rj.gov.br/wp-content/uploads/2015/08/Lei-Organica.pdf >. Acesso em jun.2016.

FARENZENA, Nalú. Controle institucional em políticas federais de educação básica no Brasil. Revista Brasileira de Política e Administração da Educação, Goiânia, v. 26, n. 2, p. 237265, 2010.

GUAPIMIRIM. Lei Orgânica de Guapimirim, de 30 de junho de 1993. Disponível em: <http://www.camaradeguapimirim.rj.gov.br/leis/leiorganica.pdf>. Acesso em: 01 jun. 2016.

ITABORAÍ. Lei Orgânica de Itaboraí, de 5 de abril de 1990. Disponível em: <http://portalservicos.ecg.tce.rj.gov.br/webforms/arquivos/legislacao/J01719__lei_organica_ITABORA\%C3\%8D.pdf>. Acesso em: 01 jun. 2016.

ITAGUAÍ. Lei Orgânica de Itaguaí, de 02 de agosto de 1990. Disponível em: <http://portalservicos.ecg.tce.rj.gov.br/webforms/arquivos/legislacao/J041772_-_Lei_ org\%C3\%A2nica_Itagua\%C3\%AD_COM_alts_incorp_2012.pdf>. Acesso em: 01 jun. 2016.

JAPERI. Lei Orgânica de Japeri, de 26 de novembro de 1993. Disponível em: <http://camarajaperi.rj.gov.br/pdf/Lei_Organica_-_Japeri.pdf>. Acesso em: 01 jun. 2016.

LEME, Maria Carolina; PAREDES, Ricardo; SOUZA, André Portela. A municipalização do EF e Seu impacto sobre a proficiência no Brasil. In: VELOSO, Fernando et al. Educação básica no Brasil - construindo o país do futuro. Rio de Janeiro: Campus-Elsevier, 2009.

MACHADO, Marcelo da Silva. Cadê o dinheiro que estava aqui: o Fundeb no Rio de Janeiro sob a ótica dos perdedores. In: ENCONTRO DA ASSOCIAÇÃO NACIONAL DE PESQUISA EM FINANCIAMENTO DA EDUCAÇÃO - FINEDUCA, 3, 2015, Gramado. Anais... Gramado: Fineduca, 2015. p. 277-291.

MAGÉ. Lei Orgânica de Magé, de 05 de abril de 1990. Disponível em: <http://www.mage.rj.gov.br/wp-content/uploads/2016/01/Lei-001-de-1990-LEI-ORG\%C3\%82 NICA-DO-MUNIC\%C3\%8DPIO.pdf>. Acesso em: 01 jun. 2016.

MARICÁ. Lei Orgânica de Maricá, de 05 de abril de 1990. Disponível em: <http://portalservicos.ecg.tce.rj.gov.br/webforms/arquivos/legislacao/J042198_-_Lei_Org\% C3\%A2nica_Maric\%C3\%A1_COM_alts.pdf>. Acesso em: 01 jun. 2016.

MESQUITA. Lei Orgânica de Mesquita, de 05 de abril de 1991. Disponível em: <http://portalservicos.ecg.tce.rj.gov.br/webforms/arquivos/legislacao/J01312___Lei_Org \%C3\%A2nica_Mesquita.pdf>. Acesso em: 01 jun. 2016.

MILITÃO, Sílvio César Nunes. Fundeb: mais do mesmo? Nuances: estudos sobre Educação, São Paulo, v. 18, n. 19, p. 127-138, 2011. 
O (im)pacto federativo e financiamento da educação

NILOPOLIS. Lei Orgânica de Nilópolis, de 05 de abril de 1990. Disponível em: $<$ http://portalservicos.ecg.tce.rj.gov.br/webforms/arquivos/legislacao/J01320__Lei_Org\%C3\%A2nica_Nil\%C3\%B3polis.pdf>. Acesso em: 01 jun. 2016.

NITERÓI. Lei Orgânica de Niterói, de 05 de abril de 1990. Disponível em: $<$ http://portalservicos.ecg.tce.rj.gov.br/webforms/arquivos/legislacao/J01322_-

_Lei_Organica_Niter\%C3\%B3i_alt_at\%C3\%A9_emenda_38_2012.pdf>. Acesso em: 01 jun. 2016.

NOVA IGUAÇU. Lei Orgânica de Nova Iguaçu, de 30 de maio 1990. Disponível em: <http://www.cmni.rj.gov.br/legislacao/lom/lei_organica_2004.pdf>. Acesso em: 01 jun. 2016.

OLIVEIRA, Romualdo Portela; SOUSA, Sandra Zákia. O federalismo e sua relação com a educação no Brasil. In: OLIVEIRA, Romualdo Portela; SANTANA, Wagner (Org.). Educação e federalismo no Brasil: combater as desigualdades, garantir a diversidade. Brasília: UNESCO, 2010. p. 13-35.

OLIVEIRA, Romualdo Portela. O Direito à educação na Constituição de 1988 e seu reestabelecimento pelo sistema de justiça. Revista Brasileira de Educação, Rio de Janeiro, v. 11, p. 61-74, 1999.

PARACAMBI. Lei Orgânica de Paracambi, de 05 de abril de 1990. Disponível em: $<$ http://www.paracambi.rj.gov.br/Legislacao/lei_organica_paracambi.pdf >. Acesso em: 01 jun. 2016.

PINTO, José Marcelino de Rezende. A política recente de fundos para o financiamento da educação e seus efeitos no pacto federativo. Educação e Sociedade, Campinas, v. 28, n. 100, p. 877-897, 2007.

PINTO, José Marcelino de Rezende. Financiamento da educação básica. A divisão de responsabilidades. Retratos da Escola, Brasília, v. 6, n. 10, p. 155-172, 2012.

QUEIMADOS. Lei Orgânica de Queimados, de 23 de outubro de 1993. Disponível em: $<$ http://portalservicos.ecg.tce.rj.gov.br/webforms/arquivos/legislacao/J01385__Lei_Org\%C3\%A2nica_Queimados_consolidado_13._mai. 2005_.pdf>. Acesso em: 01 jun. 2016.

RIO BONITO. Lei Orgânica de Rio Bonito, de 20 de abril de 1990. Disponível em: $<$ http://portalservicos.ecg.tce.rj.gov.br/webforms/arquivos/legislacao/J02093_-

_Lei_Org\%C3\%A2nica_Rio_Bonito.pdf>. Acesso em: 01 jun. 2016.

RIO DE JANEIRO. Lei Orgânica do Rio de Janeiro, de 5 de abril de 1990. Disponível em: $<$ http://www.rio.rj.gov.br/dlstatic/10112/4946719/4126916/Lei_Organica_MRJ_comaltdo205. pdf>. Acesso em: 01 jun. 2016.

SÃO GONÇALO. Lei Orgânica de São Gonçalo, de 23 de outubro de 1993. Disponível em: <http://portalservicos.ecg.tce.rj.gov.br/webforms/arquivos/legislacao/J02350_Lei_org\%C3\%A 2nica_S\%C3\%A3o_Gon\%C3\%A7alo-atualizada_em_nov_2006.pdf>. Acesso em: 01 jun. 2016.

SÃO JOÃO DE MERITI. Lei Orgânica de São João de Meriti. Disponível em: <http://portalservicos.ecg.tce.rj.gov.br/webforms/arquivos/legislacao/J01478__Lei_Org\%C3 
O (im)pacto federativo e financiamento da educação

\%A2nica_S\%C3\%A3o_Jo\%C3\%A3o_de_Meriti_COM_altera\%C3\%A7\%C3\%B5es.pdf>. Acesso em: 01 jun. 2016.

SARI, Marisa Timm. Regime de colaboração intergovernamental na educação: a experiência pioneira do rio Grande do Sul. Série Cadernos ANPAE, Porto Alegre, ANPAE, n. 4, 2007.

SEROPÉDICA. Lei Orgânica de Seropédica, de de 30 de junho de 1997. Disponível em: $<$ http://portalservicos.ecg.tce.rj.gov.br/webforms/arquivos/legislacao/J02108_-

_Lei_Org\%C3\%A2nica_Serop\%C3\%A9dica.pdf>. Acesso em: 01 jun. 2016.

SOUZA, Celina. Federalismo e Descentralização na Constituição de 1988: Processo Decisório, Conflitos e Alianças. Dados, Rio de Janeiro, v. 44, n. 3 p. 513-560, 2001.

SOUZA, Donaldo Bello de; RAMOS, Marise Nogueira; LUIZ, Neise de. Regime de Colaboração entre os entes federados e a cobertura da educação profissional municipal. Série Cadernos ANPAE, Porto Alegre, ANPAE, n. 4, 2007.

Marcelo da Silva Machado é professor da Educação Básica da rede municipal de Macaé (RJ). Mestre em Saúde Pública e Doutorando em Educação. Bolsista Capes/CNPq.

E-mail: msmmg@msn.com 


\section{Editores do volume 7}

José Marcelino de Rezende Pinto - Universidade de São Paulo, São Paulo/SP, Brasil

Nalú Farenzena - Universidade Federal do Rio Grande do Sul, Porto Alegre/RS, Brasil

\section{Comitê Editorial}

José Marcelino de Rezende Pinto - Universidade de São Paulo, Brasil

Juca Gil - Universidade Federal do Rio Grande do Sul, Brasil

Theresa Adrião - Universidade Estadual de Campinas, Brasil

Ângelo Ricardo de Souza - Universidade Federal do Paraná, Brasil

Márcia Aparecida Jacomini - Universidade Federal de São Paulo, Brasil

\section{Conselho Editorial}

\section{Alejandro Morduchowicz}

Universidad Pedagógica, Provincia de Buenos Aires, Argentina

Fernanda Saforcada

Universidade de Buenos Aires, Argentina

Jacques Velloso

Universidade de Brasília, Brasil

João Monlevade

Senado Federal, Brasil

Jorge Abrahão de Castro

Instituto de Pesquisa Econômica Aplicada / IPEA, Brasil

Juca Gil

Universidade Federal do Rio Grande do Sul, Brasil

Lisete Regina Gomes Arelaro

Universidade de São Paulo, Brasil

Luis Carlos Sales

Universidade Federal do Piauí, Brasil

Luiz de Sousa Junior

Universidade Federal da Paraíba, Brasil

Luiz Fernandes Dourado

Universidade Federal de Goiás, Brasil

Magna França

Universidade Federal do Rio Grande do Norte, Brasil

Maria Beatriz Luce

Universidade Federal do Pampa, Brasil

Universidade Federal do Rio Grande do Sul, Brasil

Marcos Edgar Bassi

Universidade Federal do Paraná, Brasil

Maria Dilnéia Espíndola Fernandes

Universidade Federal de Mato Grosso do Sul, Brasil

\section{Nalú Farenzena}

Universidade Federal do Rio Grande do Sul, Brasil

Nelson Cardoso do Amaral

Universidade Federal de Goiás, Brasil

Nicholas Davies

Universidade Federal Fluminense, Brasil

Rosana Evangelista Cruz

Universidade Federal do Piauí, Brasil

Rosana Gemaque

Universidade Federal do Pará, Brasil

Robert E. Verhine

Universidade Federal da Bahia, Brasil

Romualdo Portela de Oliveira

Universidade de São Paulo, Brasil

Theresa Adrião

Universidade Estadual de Campinas, Brasil

Tristan McCowan

University of London, Reino Unido

Vera Jacob

Universidade Federal do Pará, Brasil

Vera Peroni

Universidade Federal do Rio Grande do Sul, Brasil

Vitor Henrique Paro

Universidade de São Paulo, Brasil

\section{Equipe editorial}

Apoio ao Comitê Editorial: Patrícia Balthazar Garcia

Diagramação, Revisão de português e normalização: Edson Leonel de Oliveira

Revisão de inglês: Ananyr Porto Fajardo 